\title{
INFERRING KINSHIP FROM BEHAVIOUR: MATERNITY DETERMINATIONS IN YELLOW BABOONS
}

\author{
BY JEFFREY WALTERS* \\ Allee Laboratory of Animal Behavior, The University of Chicago, 5712 S. Ingleside Ave., Chicago, \\ Illinois 60637
}

\begin{abstract}
Kinship is commonly inferred from behaviour in primate field studies, but the validity of such inferences has not yet been documented. A comparison of the relationships of six three-year-old yellow baboon (Papio cynocephalus) females with 14 adult females showed that when a juvenile's mother was living she could easily be identified from behavioural data. The most useful behaviour in this context was Presenting For Grooming. When the mother was not living, however, the juvenile compensated by forming a strong relationship with a less closely related or unrelated adult female. If compensation also occurs in other populations and other species, past attempts to infer kinship from behaviour have probably included a few cases in which a female was incorrectly identified as a juvenile's mother. Multivariate statistical techniques revealed differences between mother-daughter relationships and strong relationships based on compensation among other individuals. These differences involved comparisons of the frequencies of certain behaviours (frequency of Grooming by adult versus frequency of Grooming by juvenile, frequency of Grooming versus frequency of aggression) as well as the magnitudes of frequencies (amount of Grooming, number of Interventions).
\end{abstract}

In field studies of primates, the identity of an individual's mother is often inferred from observed behavioural relationships. This has been done with chimpanzees (Pan troglodytes) (Van Lawick-Goodall 1968), baboons (Papio spp.) (Cheney 1977, 1978a, 1978b; Lee \& Oliver 1979), and Japanese macaques (Macaca fuscata) (Kawai 1965; Kurland 1977), among others. For very young animals, persistent suckling from one female identifies that female as the mother. Although females do adopt and suckle infants that are not their own (Marsden \& Vessey 1968; Berman, personal communication), this phenomenon is so rare that suckling is a very reliable criterion for identification of maternity (Koyama 1967; but see Kurland 1977).

In all of the above studies, however, the identities of mothers of fully weaned juveniles, and in some cases even of adults (Kurland 1977), were inferred. The criteria used in these cases include play, grooming, proximity, interventions in ongoing agonistic interactions, and unrestricted access to infants (Lee \& Oliver 1979); proximity, grooming, presenting for grooming, and sleeping in proximity (Cheney, personal communication); grooming and play (Van Lawick-Goodall 1968); and close association (Kurland 1977).

Evidence for the reliability of inferences about older animals consists of correlations between

*Present address: Museum of Vertebrate Zoology, 2593 Life Sciences Building, University of California, Berkeley, California 94720 . kinship and behaviour among individuals whose kin relationships are known. Such data exist for proximity, grooming, play, and interventions in rhesus macaques (M. mulatta) (Sade 1965, 1972a; Kaplan 1977, 1978; Berman 1978), for grooming in Japanese macaques (Yamada 1963), and for interventions in other macaques (Massey 1977; De Waal 1977). This evidence is inadequate bebecause, except for Yamada's study (1963), it considers only mean relationships, whereas the validity of inferences depends greatly on variance within relationship classes. The means of two groups may differ, but if there is sufficient overlap between the groups it may be impossible to determine to which group a particular case belongs (see Yamada 1963).

Primates generally are long-lived and bear young infrequently. Yellow baboon ( $P$. cynocephalus) females, for example, may live at least as long as 15 years, and probably considerably longer. They bear their first infant at about 6.5 years of age, and the interval between births of viable offspring is about 22 months (J. Altmann et al. 1977). Genealogies based on known relationships thus take many years to establish. It is important to establish the validity of kinship inferences, since the information obtained from them is so valuable.

Two other factors make this an especially urgent task. First, the effects of kinship on behaviour are currently of much interest. Lacking evidence of the validity of kinship inferences, studies that use such inferences when examining 
the effects of kinship on behaviour, such as those listed in the second paragraph, are dangerously circular. Second, inferences about kinship are becoming increasingly accepted. For example, inferred and known relationships clearly distinguished in Kawai (1965) are no longer differentiated in Mori (1975), and Lee \& Oliver (1979) justified the criteria they used in inferring the identities of the mothers of fully weaned juveniles by citing Kurland (1977). Kurland's study, though an excellent one, examines correlations between the frequencies of various behaviours and kinship, and uses some inferred kin relationships, as well as known relationships, in establishing these correlations (see Fig. 3 in Kurland 1977). This kind of study is not concerned with the accuracy of maternity determinations, nor does it provide directly the data necessary to examine the issue. Although one could compute overlap between groups from the standard errors and sample sizes provided by Kurland (e.g. Fig. 4 in Kurland 1977), to my knowledge no one has done so.

The purpose of the present study is to determine, using individuals from a population in which maternal identities are known, the validity of kinship inferences based on behaviour, the best criteria for making such inferences, and the circumstances under which errors may occur.

As in most studies of kinship and behaviour in primates, relatedness through patrilines will be ignored. Paternity is very difficult to determine, since females often mate with several males. If relatedness through patrilines does affect behaviour, its effect will be to make maternity determinations more difficult. In this study, then, paternity may be considered a confounding factor.

\section{Source of Data}

\section{Methods}

Yellow baboons were studied for 11 months (September 1976 to July 1977) in Amboseli National Park, Kenya. The Amboseli population, and particularly the study group, known as Alto's group, have been the subject of a longitudinal study of behaviour and ecology (Altmann \& Altmann 1970; Hausfater 1975; J. Altmann et al. 1977; J. Altmann 1980; Post 1978).

I sampled the behaviour of six juvenile females, age 33 to 41 months at the beginning of the study, by focal sampling (J. Altmann 1974). Females do not reach menarche in Amboseli until 4.5 to 5 years of age (J. Altmann et al. 1977), but these juveniles were already becoming integrated into adult female society. For example, they were in the process of acquiring their adult dominance ranks (Walters 1980). They still played frequently, but in many aspects of behaviour they resembled adults more than younger juveniles. The frequency with which each of these juveniles directed social behaviours toward and received social behaviours from each of the 14 adult females in the group was recorded (see Appendix for definitions of behaviours). These frequencies are comparable between dyads, because equal numbers of samples were collected from each juvenile at each sampled time of day. A total of $80 \mathrm{~h}$ of samples was collected from each juvenile. These same data were collected from non-focal individuals concurrent with focal samples, and from all individuals when not focal sampling; these records are considered ad libitum samples of behaviour (J. Altmann 1974). Over $1470 \mathrm{~h}$ were spent with Alto's group during the study.

Based on the criterion of an infant consistently suckling from a single female, the mothers, and hence younger maternal siblings, of all individuals seven years of age or less were known. Thus, the mothers of all of the focal juveniles were known, as well as their younger siblings and older siblings seven years of age or less. Four of the juveniles' mothers were still living, and one of those whose mother had died had an adult female sister in the group. Data analysis compares the four mother-daughter dyads, the sibling dyad, and the remaining 79 adult-femalejuvenile dyads. These 79 dyads probably include distant kin whose relationships were not known, but it is extremely unlikely that any of these were as closely related as sisters.

\section{Data Analysis}

The data were first examined graphically to determine how reliably close kinship, motherdaughter and siblings, could be inferred from the frequencies of particular behaviours. This simple analysis shows the extent to which kin dyads stand out from the others in the frequency with which a behaviour, or set of behaviours, is performed. Following this analysis, multivariate techniques, which consider both the frequencies of particular behaviours and the relationships between the frequencies of different behaviours, were employed. These methods provide a quantitative means for comparing total relationships.

First, stepwise discriminant analysis (BMDP7M, Dixon \& Brown 1977) was performed, using 
the 5 close kin dyads as one group and the 79 remaining dyads as the other. The variables used in the analysis were the frequencies with which each of the behaviours listed in the Appendix were recorded, each dyad providing one datum for each behaviour. This method computes the best possible means by which the groups, in this case close kin and others, can be separated.

Discriminant analyses were also performed considering only adult behaviour (variables were frequencies with which adults directed behaviours toward juveniles), and considering only juvenile behaviour (variables were frequencies with which juveniles directed behaviours toward adults). Mild Aggression, Severe Aggression, and Displacements could not be included in these analyses because their expression was almost exclusively limited to the dominant member of a dyad, which in some cases was the juvenile and in others the adult (Walters 1980).

A final discriminant analysis was performed on the variables used in the analysis of adult behaviour; those used in the analysis of juvenile behaviour; and Mild Aggression, Severe Aggression, and Displacements. This analysis provides the most detailed description of relationships in that all behaviours are considered, and most are divided into those occurrences that were performed by adults and those that were performed by juveniles.

The data were not multivariate normal as assumed in discriminant analysis: most behaviours had an excess of scores of zero and a few conspicuous high scores (outliers). The effect of this violation was examined by repeating the analyses using square-root-transformed data. This transformation eliminated the problem of outliers, but many behaviours were still conspicuously truncated at zero. Thus, the analyses were again repeated using a distribution-free technique, the SAS nearest-neighbour procedure (Barr et al. 1976). This procedure determines the nearest neighbours of each dyad in $N$-dimensional space (measured as Euclidean distance), $N$ being the number of variables (in this case behaviours), and classifies the dyad into the group (close kin or other) to which most of its neighbours belong. Because the close kin group was small ( 5 cases), the number of neighbours used was limited to 2 or 3 .

An alternative method of analysing the data is to examine the proportions of an individual's acts that were directed toward various other individuals, rather than the actual frequencies of the acts (e.g. Sade 1972b). This allows one to correct for characteristic differences between individuals based on, for example, dominance rank or personality differences, in the frequency with which particular behaviours are performed or received. Such individual differences are especially troublesome if one wants to perform statistical tests on data taken from a series of dyads in which a particular individual is a member of more than one dyad, because they prohibit one from assuming that dyads are independent. There were very few such differences among the juveniles, but they were evident among the adult females. One factor that might account for such differences is whether or not a female was caring for a small infant: juvenile females are attracted to infants and their mothers (Hrdy 1976), and may interact with the mothers frequently as a result (Cheney 1978a; J. Altmann 1980). To examine this effect, the analyses were repeated dividing the non-kin dyads into those in which the adult member was caring for a small infant and those in which she was not. Other consequences of considering proportions rather than frequencies are commented upon where appropriate below.

Only 20 Interventions occurred in focal samples; therefore, ad libitum and focal data were combined in computing frequencies of Interventions. If some individuals were more visible than others, this introduces a bias into comparisons among dyads. Interventions thus were not used in the multivariate analyses.

\section{Results \\ Examinations of Particular Behaviours}

Most behaviours were not useful in distinguishing close kin from others because of overlap between the two groups. For most behaviours, the distributions of frequencies for close kin and others appeared similar (e.g. Displacements, Severe Aggression; Fig. 1A and 1B). For a few, the distributions appeared different, but there was still considerable overlap between the two (e.g. Mild Aggression, Fig. 1C).

The two groups separated clearly on the basis of Grooming, Presenting For Grooming, and Interventions. Each of these behaviours separated six dyads, including the five kin dyads and one other, from the remaining dyads (Fig. 2). The deviant non-kin dyad was Janet-Oval for Grooming and Presenting For Grooming, and Fanny-Fem for Interventions (see description of dyads in Table I). 
Results were similar when only adult behaviour or only juvenile behaviour was considered, except that overlap between close kin and others in the frequency of Interventions eliminated this behaviour as a means of distinguishing between the two groups (Figs 3C and 4C). Grooming by adults best separated the groups (Fig. 3A),

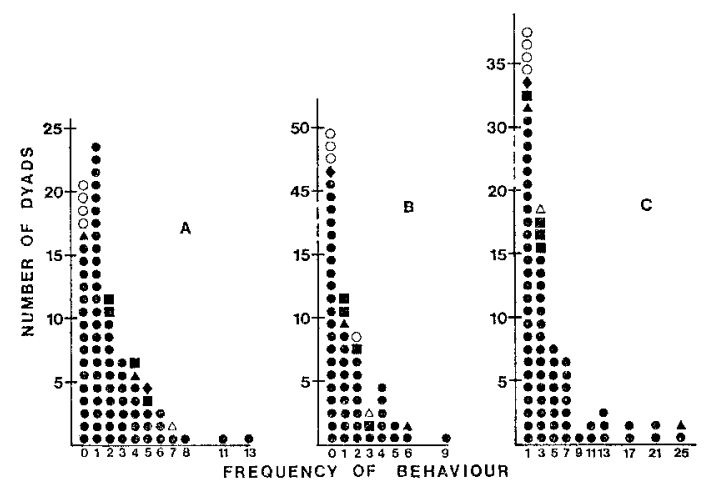

Fig. 1. Histograms of aggressive behaviours, (A) Displacement, (B) Severe Aggression, and (C) Mild Aggression. Open circles denote mother-daughter dyads, the open triangle denotes the sibling dyad, and closed circles denote dyads not involving close kin. The other symbols denote unusual dyads from the latter group (see Table I): Janet-Oval is denoted by a closed diamond; Cete-Vee Fanny-Vee, Janet-Vee, and Striper-Vee are denoted by closed squares; and Dotty-Handle and Fanny-Fem are denoted by closed triangles. Frequency of behaviour is plotted against the number of dyads exhibiting that frequency. Note the overlap between close kin and others. whereas Grooming by juveniles did not clearly separate them (Fig. 4A). Presenting For Grooming by both adults and juveniles grouped JanetOval with the close-kin dyads (Figs $3 B$ and $4 B$ ).

If mother-daughter relationships were inferred from this examination of behavioural frequencies, the inferences made would generally be correct. Four dyads would be correctly classified as mother-daughter pairs, and 78 dyads as nonpairs. However, one dyad not involving close kin (Janet-Oval) would probably be incorrectly classified as a mother-daughter pair, as would the sibling pair. Janet-Oval differs slightly from the mother-daughter pairs in its Intervention relationship, and the sibling pair differs in its aggression relationship (Figs 1-4), but these

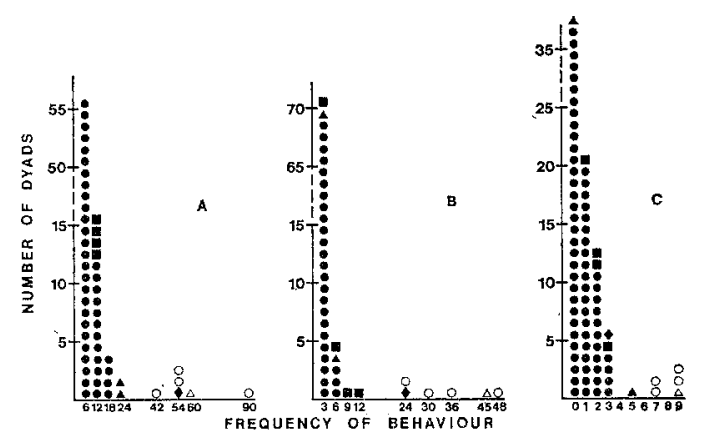

Fig. 2. Histograms of behaviours useful in distinguishing close kin from others; (A) Groomed, (B) Presented For Grooming, and (C) Intervened. Key as in Fig. 1.

Table I. Descriptions of Important Juvenile-Adult Female Dyads

\begin{tabular}{|c|c|}
\hline Dyad & Description* \\
\hline Dotty-Spot & $\begin{array}{l}\text { Sisters; Spot had one-year-old daughter; their mother was deceased, but they had a two-year-old } \\
\text { sister. }\end{array}$ \\
\hline Dotty-Handle & $\begin{array}{l}\text { Unrelated (more distantly related than cousins); Handle had one-year-old son, and bore a second } \\
\text { infant near the end of the study. }\end{array}$ \\
\hline Striper-Mom & Daughter-mother: Mom also had a one-year-old son. \\
\hline Striper-Vee & $\begin{array}{l}\text { Unrelated (probably more distantly related than cousins); Vee was a young adult female (seven } \\
\text { years old) that had borne one infant, which died at one month of age; Vee's mother was deceased, } \\
\text { and she had no known kin in the group. }\end{array}$ \\
\hline Nazu-Preg & Daughter-mother; Preg also had a six-year-old son and an infant daughter. \\
\hline Cete-Scar & Daughter-mother; Scar also had a two-year-old daughter. \\
\hline Cete-Vee & Unrelated (probably more distantly related than cousins). \\
\hline Fanny-Oval & Daughter-mother; Oval had also a two-year-old son and an infant daughter. \\
\hline Fanny-Vee & Unrelated (more distantly related than cousins). \\
\hline Fanny-Fem & $\begin{array}{l}\text { Unrelated (probably more distantly related than cousins); Fem had a two-year-old son, and bore a } \\
\text { second infant, which died at three months of age, during the study. }\end{array}$ \\
\hline Janet-Oval & $\begin{array}{l}\text { Unrelated? (Oval could be as closely related to Janet as aunt or cousin, and was possibly her closest } \\
\text { living relative, but they may be unrelated); Janet is daughter of Judy, who was deceased; Janet had } \\
\text { no known kin in group. }\end{array}$ \\
\hline Janet-Vee & Unrelated (more distantly related than cousins). \\
\hline
\end{tabular}

*Guesses about possible relationships among individuals classified as unrelated are based on demographic factors, relative dominance ranks (see Discussion), and known histories. 
differences are probably too slight to prevent misclassification.

Considering proportions rather than frequencies only accentuated the strength of the Janet-Oval relationship, since Janet was the least active juvenile in Grooming and Presenting For Grooming. Considering proportions also failed to reveal differences between the sibling dyad and the mother-daughter dyads.

These two particular errors might be avoided by considering demographic factors. Spot was too young by two years to be the mother of her sister Dotty (but current aging criteria for adults are not accurate enough for one to eliminate Spot as a possible mother of Dotty; J. Altmann et al. 1977), and Janet and Fanny were too close in age to be sisters, unless they were twins. (Janet and Oval might then be classified as sisters, which is also incorrect.)

One cannot count on demographic cues as a consistent means of avoiding inference errors. Apparently, both motherless juveniles compensated for the loss of their mother by forming a strong relationship, indistinguishable at a gross level from relationships of true mother-daughter pairs, with another adult female. In the next section, I consider whether one can avoid misclassifying such dyads by a more detailed examination of behaviour.

\section{Discriminant Analysis}

Close kin and others were discriminated well using untransformed data. The first variable entered in all analyses was either Grooming or Presenting For Grooming, and this first behaviour always classified as many dyads correctly by itself as did any combination of behaviours thereafter (Table II). In both analyses that in-
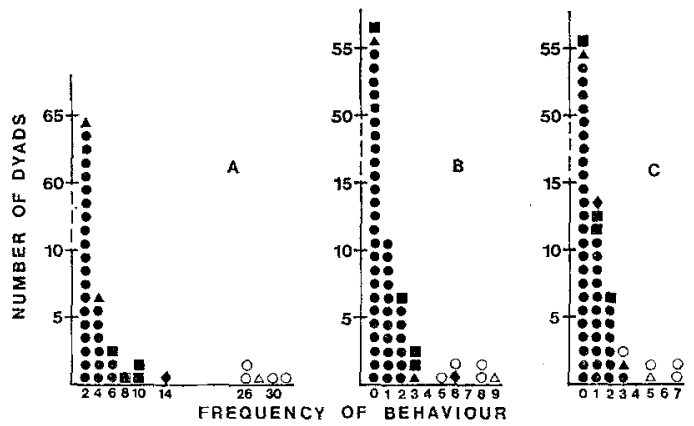

Fig. 3. Histograms of adult behaviour: (A) Groomed, (B) Presented For Grooming, and (C) Intervened. Key as in Fig. 1. cluded aggression variables, Displacement was the first behaviour other than a grooming behaviour entered into the discriminant function. A variety of other behaviours were entered in the final steps of the analyses.

Janet-Oval was consistently the most kin-like of the non-kin dyads, and was incorrectly classified in two of the four analyses. This is perhaps best appreciated by examining plots of canonical variables, which are the linear combinations of the variables that best discriminate the groups (Fig. 5). When only juvenile behaviour or the behaviour of the dyad as a unit was considered, Janet-Oval was clearly more like the close-kin dyads than the other dyads (Fig. 5, A and B). When only adult behaviour was considered, this dyad was intermediate between the two groups rather than clearly in either one (Fig. 5C). It was only when the combination of adult behaviour, juvenile behaviour, and aggressive behaviour was considered that Janet-Oval was more similar to the other dyads than to the closekin dyads (Fig. 5D).

The sibling dyad did not stand out among the kin dyads in any of the analyses. Several unrelated dyads were exceptional in not clearly belonging to either of the two groups rather than with the remaining unrelated dyads in one or more of the analyses (Fig. 5). Nearly all of these included adult female Vee.

The results of these analyses can be summarized as follows. (1) Close kin were readily distinguished from others except for one particular non-kin dyad, Janet-Oval. (2) Discrimination was based on (a) the frequency of Grooming and

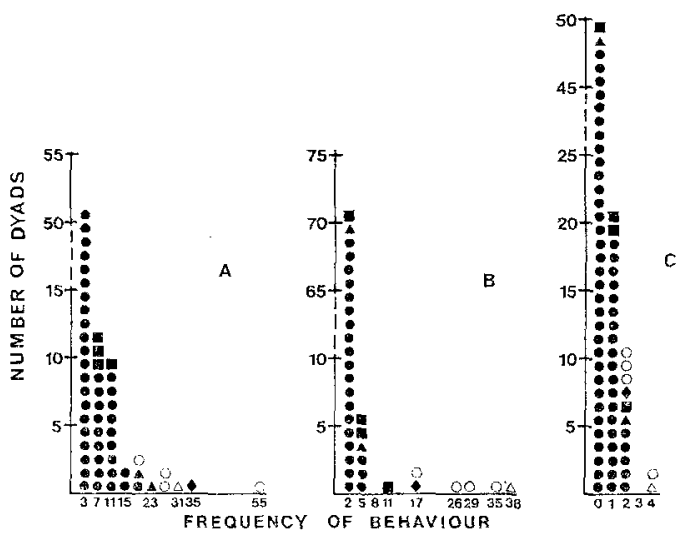

Fig. 4. Histograms of juvenile behaviour: (A) Groomed, (B) Presented For Grooming, and (C) Intervened. Key as in Fig. 1. 
Presenting For Grooming (much higher among close kin); (b) the relationship between these grooming variable frequencies and the frequency of Displacements (close-kin dyads had high grooming frequencies and low Displacement frequencies, while other dyads with high grooming frequencies also had high Displacement frequencies); and (c) the relationship between the frequency of Grooming by the juvenile and the remaining Grooming and Presenting For Grooming frequencies, which is a measure of the reciprocity of the grooming relationship (strong grooming relationships among close kin were more reciprocal than those among others, which consisted mostly of grooming by the juvenile). (3) With respect to reciprocity of grooming and the relationship between grooming variables and Displacements, Janet-Oval resembled the other non-kin dyads rather than the close-kin dyads (see Figs 1-4). (4) Dotty-Spot, the sibling dyad, resembled the mother-daughter dyads in the frequency of Grooming and Presenting For Grooming and in reciprocity of grooming. However, they exhibited more Displacements than the mother-daughter dyads. (5) Presenting For
Grooming, which is not usually measured in primate field studies, was a better indicator of close kinship than Grooming. (6) All of the nonmother-daughter relationships that most closely resembled those of mother-daughter pairs (Dotty-Spot, Janet-Oval, Striper-Vee, Cete-Vee, Fanny-Vee, Janet-Vee) involved individuals lacking a living mother or daughter (see Table I). This again suggests that baboons compensate for the loss of kin by forming close relationships with other individuals.

\section{The Reliability of the Results of Discriminant Analysis}

The results of transformation, nearest-neighbour analysis, and dividing the non-kin group into subgroups all indicate that the results of the initial discriminant analysis are reliable.

Effect of transformation. None of the results were altered by transformation of the data. Some discriminations were slightly improved by transformation, whereas others were made slightly worse, and the same behaviours were used to discriminate the two groups. The differences consisted of slight changes in the relation-

Table II. Summary of Discriminant Analysis of Close Kin and Other Groups

\begin{tabular}{|c|c|c|c|c|}
\hline Step & Variable entered & $F^{*}$ to enter & Next largest $F$ & $\begin{array}{l}\text { Cases correctly } \\
\text { classified by } \\
\text { jack-knifing* }\end{array}$ \\
\hline \multicolumn{5}{|c|}{ A. All Behaviour } \\
\hline 1 & Presented For Grooming & 410.73 & 191.37, Groomed & $83 / 84$ \\
\hline $\begin{array}{l}2 \\
3\end{array}$ & $\begin{array}{l}\text { Displaced } \\
\text { None }\end{array}$ & 4.23 & $\begin{array}{l}\text { 0.98, Muzzle-Sniffed } \\
\text { 0.43, Embraced }\end{array}$ & $83 / 84$ \\
\hline \multicolumn{5}{|c|}{ B. Juvenile Behaviour Only } \\
\hline 1 & Presented For Grooming & 404.60 & 74.00, Groomed & $82 / 84$ \\
\hline 2 & Affiliative-Sexual Behaviour & 1.66 & 1.31 , Touched & $82 / 84$ \\
\hline 3 & Touched & 1.95 & 0.94 Groomed & $82 / 84$ \\
\hline 4 & Groomed & 1.21 & 0.10 , Muzzle-Sniffed & $82 / 84$ \\
\hline 5 & None & & 0.05 , Muzzle-Sniffed & \\
\hline \multicolumn{5}{|c|}{ C. Adult Behaviour Only } \\
\hline 1 & Groomed & 488.98 & 186.68, Presented For Grooming & $84 / 84$ \\
\hline 2 & Touched & 2.70 & 0.41, Affiliative-Sexual Behaviour & $84 / 84$ \\
\hline & None & & 0.27, Embraced & \\
\hline \multicolumn{5}{|c|}{ D. Combination of Adult Behaviour, Juvenile Behaviour, and Aggressive Behaviour } \\
\hline 1 & A.t Groomed & 488.98 & $404.60, \mathrm{~J} . \dagger$ Presented For Grooming & $84 / 84$ \\
\hline 2 & J. Presented For Grooming & 11.35 & 5.64 , Displaced & $83 / 84$ \\
\hline 3 & J. Groomed & 6.86 & 5.56, Displaced & $84 / 84$ \\
\hline 4 & Displaced & 5.35 & 2.64, A. Muzzle-Sniffed & $84 / 84$ \\
\hline 5 & A. Touched & 1.93 & 1.44, A. Muzzle-Sniffed & $84 / 84$ \\
\hline
\end{tabular}

*This is the $F$ statistic of the one-way analysis of covariance of the variable entered where the covariates are the previously entered variables (Dixon \& Brown 1977).

**In this procedure, each dyad is eliminated in turn from the calculations, and then is assigned to one or the other of the groups based on the Mahalanobis distance between it and the group means computed from the remaining dyads.

$\dagger$ A. denotes adult behaviour; $\mathbf{J}$. denotes juvenile behaviour. 
ship of Janet-Oval to the close kin and other groups, and of the relationships of a few of the other unusual non-kin dyads to the two groups.

Nearest-neighbour analysis. The results of nearest-neighbour analysis were nearly identical to the results of discriminant analysis. When only two neighbours were considered, and the analysis was restricted to only adult behaviour or the behaviour of the dyad as a unit, only
Dotty-Spot, the sibling dyad, was incorrectly classified. Two other dyads, Janet-Oval and Cete-Scar (a mother-daughter dyad), became difficult to classify if the number of neighbours was increased or the data were transformed. The differences between the two problematic dyads (Janet-Oval, Dotty-Spot) and the motherdaughter pairs were more evident in nearestneighbour analysis than in discriminant analysis

A
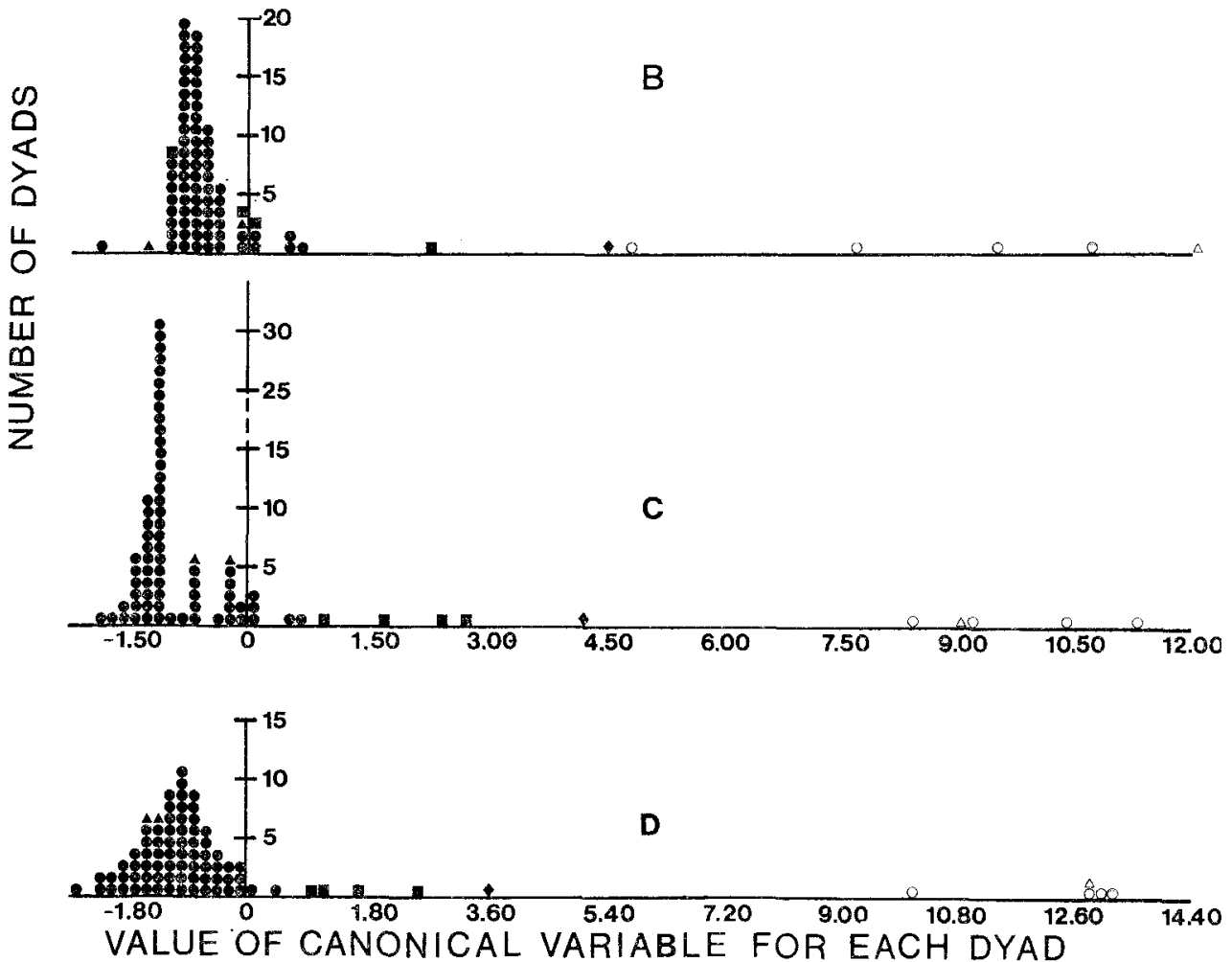

Fig. 5. Histograms of the canonical variable for discriminant analysis of untransformed data, using (A) all behaviour; (B) juvenile behaviour only; (C) adult behaviour only; and (D) a combination of adult behaviour, juvenile behaviour, and aggressive behaviour (see text). The values of the canonical variable are plotted against the number of dyads at each value. Symbols as in Fig. 1. 
because of differences in the weightings of the behaviours in the two procedures, but the magnitude of the separation between close kin and the bulk of the other dyads was reduced in the nearest-neighbour analysis.

Effect of dividing the non-kin group. Dividing the non-kin dyads into those that included a female that was tending an infant and those that did not include such a female did not affect discrimination of close kin from others. Relationships based on attraction to an infant (e.g. Fanny-Fem, Dotty-Handle) involved little or no Presenting For Grooming or Grooming by the adult (Figs 2-4), and often involved considerable aggression (Fig. 1). They were thus very easily distinguished from close-kin relationships and kin-like relationships among non-kin (Fig. 5).

Although particular juveniles were attracted to particular females with infants, most such females were treated like other non-kin. As a result, the two non-kin groups were not distinguishable. Thus reproductive state did not uniformly alter the activity of females with respect to all juveniles. Differences in activity among females were related to age, dominance status, and probably several other factors. These differences do not affect the results of the study, with one exception. Vee has been cited as an example of an adult female that formed strong relationships with unrelated juveniles in the absence of kin. Other explanations might account for Vee's relationships with juvenile females. For example, perhaps Vee was simply an active groomer.

\section{Discussion}

The results indicate that mothers of older female juvenile baboons can easily and reliably be detected from behaviour in cases where the mother is still living. Most affiliative behaviours were of little or no value in this regard; but Grooming, Interventions, and especially Presenting For Grooming were useful indicators of kinship. These are the kinds of behaviour most often used in maternity determinations, although Presenting For Grooming is frequently not included (see introduction).

Multivariate techniques were necessary to discriminate an unrelated dyad that contained a juvenile whose mother had died from the mother-daughter dyads. The juvenile had apparently compensated for the loss of her mother by attempting to form a strong grooming relationship with another adult female. This female Groomed the juvenile and Presented For
Grooming to her, but not nearly as often as the juvenile Groomed the adult. The adult was not less aggressive toward the juvenile as a result of the relationship; nor did she Intervene for her. Thus, the juvenile's efforts resulted in some reciprocation, but not in the kind of relationship she could expect to have with her mother. Mother-daughter relationships were characterized by a reciprocal exchange of acts that were beneficial to the recipient of the act (Grooming, Interventions), and an absence of aggression, which is presumably harmful to the recipient.

The relationship between sisters Dotty and Spot was very similar to the mother-daughter relationships. Unfortunately, one does not know if this is typical of siblings or if the relationship has been strengthened due to the death of their mother. The high frequency of aggression in the sibling dyad relative to the mother-daughter dyads may be a means of distinguishing these two kinds of relationships. However, this aggression may have been due to the uncertain dominance relationship between these sisters that resulted from the death of their mother. Because the juveniles were establishing their dominance ranks with respect to adult females during the study (Walters 1980), the frequency of aggression among sisters, and indeed among all dyads, might be higher than during other lifehistory stages.

Relationships based on attraction to infants were very one-dimensional, and were easily distinguished from kin relationships. Although the presence of a new infant often led to increased Grooming by juveniles, other aspects of the relalationship between them and the mother (adult behaviour, aggression, Presenting For Grooming, Interventions) were unchanged.

It should be emphasized that the results of this study might be specific to juvenile-femaleadult-female relationships in baboons. Behavioural compensation for the loss of the mother seems widespread among primates (see McKenna, in press, for review), although not universal (Dunbar 1979), but the nature of compensation is probably variable. Studying other species and even baboons of other ages would probably require different criteria for inferring mother-daughter relationships. Certainly the particular discriminant functions used here to discriminate close kin from others cannot be directly applied to other species. Also, maternity determinations for older juvenile males may be more complicated than for juvenile females, since males become dissociated from their 
family as they grow older (e.g. Fig. 5 in Kurland 1977). Further studies are needed to assess the generality of these results.

Bearing this reservation in mind, this study suggests that most inferences of motherdaughter relationships made in the past have been correct. This is encouraging, given the widespread use of such inferences. On the other hand, errors have probably been made in cases where the mother of a particular juvenile was no longer living. Unfortunately, such cases are likely to occur in the stable or declining populations in which maternity determinations have usually been made. Because criteria for inferences have usually been multivariate in nature, many errors due to orphaned juveniles have probably been avoided. These criteria have not been sufficiently quantitative to differentiate consistently cases like Janet-Oval and DottySpot from mother-daughter pairs, however.

The effect of errors of the frequency suggested by this study depends on how maternity determinations are used. Certainly for most kinds of demographic reconstructions, the benefits derived from kinship inferences far outweigh the costs resulting from a few errors. Even when examining behaviour, errors may not be critical. For example, circularity introduced into studies relating kinship to behaviour by such errors probably causes the correlation between kinship and behaviour to be overestimated, but it is probably not the primary cause of this correlation. In the study group, the correlation between grooming frequency and whether the interactants are mother and daughter drops from 0.89 to 0.75 if Janet-Oval and Dotty-Spot are removed from the mother-daughter group. The effect of an error of this magnitude on the validity of results will of course vary from study to study. Certainly it is too large an error to be ignored.

Such errors can be extremely misleading in certain contexts. For example, in two of the three field studies of macaques that report cases of daughters entering the adult dominance hierarchy several positions below their mother's rank, rather than immediately below their mother's rank as is usually the case, the observed discrepancies between ranks of mothers and daughters (no. 110-no. 101 in Kawai 1965; Aome-Nogi and Aome-Nofuji in Mori 1975; see also Missakian 1972) are more likely due to errors in maternity determinations than to breakdowns of the system by which daughters inherit their mothers' ranks (Kawai 1965; Koyama
1967). The possibility of inference errors should be kept in mind when considering rare phenomena such as this.

If a few errors can be tolerated, detecting mothers of older juvenile baboons is rather easy, and can be done by examining a few key behaviours, such as Presenting For Grooming. It is not a trivial exercise if extreme accuracy is desired, however. Multivariate techniques that consider relationships between behavioural frequencies, as well as the magnitudes of particular frequencies, must be employed. One should also take advantage of demographic information, known patterns of social structure such as rank inheritance, and rare events such as situations of extreme stress (Sade 1968). The prognosis resulting from this admittedly limited study is that if these procedures are followed, maternity determinations based on behaviour can be an accurate and useful tool in field studies of primates. Further studies like this one are needed to determine whether this prognosis is accurate.

\section{Acknowledgments}

I thank the Kenya Ministry of Tourism and Wildlife, Amboseli Park Warden Joseph Kioko, Dr S. Altmann, Dr J. Altmann, and Dr G. Hausfater for making this study possible. Funding was provided by the National Institute of Mental Health through a research grant to Dr S. Altmann and Dr J. Altmann (MH 19617) and a training grant (MH 15181). I thank M. Wilson, whose earlier unpublished study inspired this one, and D. Stein, whose ideas were most helpful in designing the analysis. Dr R. Thisted and R. Kass provided valuable comments on statistical methods; and Dr G. Hausfater, C. Saunders, J. Meade, D. Western, and M. Kirega provided assistance in the field. Dr D. Cheney, Dr J Altmann, and D. Stein contributed helpful comments on the manuscript, and J. Luft typed the final version. Finally, I thank my wife Beverly for countless assistances during all stages of the work.

\section{REFER EN CES}

Altmann, J. 1974. Observational study of behaviour: sampling methods. Behaviour, 49, 227-267.

Altmann, J, 1980. Baboon Mothers and Infants. Cambridge, Mass.: Harvard University Press.

Altmann, J., Altmann, S. A., Hausfater, G. \& McCuskey, S. A. 1977. Life history of yellow baboons: physical development, reproductive parameters, and infant mortality. Primates, 18, 315-330.

Altmann, S. A. \& Altmann, J. 1970. Baboon Ecology. Chicago: University of Chicago Press. 
Barr, A. J., Goodnight, J. H., Sal1, J. P. \& Helwig, J. T. 1976. A User's Guide to $S A S$ 76. Raleigh, North Carolina: SAS Institute Inc.

Berman, C. M. 1978. Social relationships among freeranging infant rhesus monkeys. Ph.D. thesis, Cambridge University.

Cheney, D. L. 1977. The acquisition of rank and the development of reciprocal alliances among freeranging immature baboons. Behav. Ecol. Sociobiol., 2, 303-318.

Cheney, D. L. 1978a. Interactions of immature male and female baboons with adult females. Anim. Behav., 26, 389-408.

Cheney, D. L. $1978 \mathrm{~b}$. The play partners of immature baboons. Anim. Behav., 26, 1038-1050.

De Waal, F. B. M. 1977. The organization of agonistic relations within two captive groups of Java monkeys (Macaca fascicularis). $Z$. Tierpsychol., 44, 225-282.

Dixon, W. J. \& Brown, M. B. 1977. BMDP Biomedical Computer Programs. Los Angeles: University of California Press.

Dunbar, R. I. M. 1979. Structure of gelada baboon reproductive units. I. Stability of social relationships. Behaviour, 69, 72-87.

Hausfater, G. 1975. Dominance and reproduction in baboons (Papio cynocephalus). Contrib. Primatol., 7. Basel: Karger.

Hrdy, S. B. 1976. Care and exploitation of nonhuman primate infants by conspecifics other than the mother. Adv. Study Behav., 6, 101-158.

Kaplan, J. R. 1977. Patterns of fight interference in freeranging thesus monkeys. Am. J. phys. Anthrop., $47,279-288$.

Kaplan, J. R. 1978. Fight interference and altruism in rhesus monkeys. Am. J. phys. Anthrop., 49, 241250.

Kawai, M. 1965. On the system of social ranks in a natural troop of Japanese monkeys: (I) basic rank and dependent rank. In: Japanese Monkeys, a Collection of Translations (Ed. by S. A. Altmann), pp. 66-86. Atlanta, Ga.: published by the editor.

Koyama, N. 1967. On dominance rank and kinship of a wild Japanese monkey troop in Arashiyama. Primates, 8, 189-216.

Kurland, J. A. 1977. Kin selection in the Japanese monkey. Contrib. Primatol., 12. Basel: Karger.

Lee, P. C. \& Oliver, J. I. 1979. Competition, dominance, and the acquisition of rank in juvenile yellow baboons (Papio cynocephalus). Anim. Behav., 27, 576-585.

Marsden, H. M. \& Vessey, S. H. 1968. Adoption of an infant green monkey within a social group. Comm. Behav. Biol. (A), 2, 275-279.

Massey, A. 1977. Agonistic aids and kinship in a group of pigtail macaques. Behav. Ecol. Sociobiol., 2, 31-40.

McKenna, H. H. In press. Aspects of infant socialization, attachment, and maternal caregiving patterns among primates: a cross-disciplinary review. Yearbook phys. Anthrop.

Missakian, E. A. 1972. Genealogical and cross-genealogical dominance relations in a group of free-ranging rhesus monkeys (Macaca mulatta) on Cayo Santiago. Primates, 13, 269-280.

Mori, A. 1975. Signals found in the grooming interactions of wild Japanese monkeys of the Koshima troop. Primates, 16, 107-140.
Post, D. G. 1978. Feeding and ranging behavior of the yellow baboon (Papio cynocephalus). Ph.D. thesis, Yale University.

Sade, D. S. 1965. Some aspects of parent-offspring and sibling relations in a group of rhesus monkeys, with a discussion of grooming. Am. J. phys. Anthrop., 23, 1-18.

Sade, D. S. 1968. Inbibition of son-mother mating among free-ranging rhesus monkeys. Sci. Psychoanal., 12, 18-38.

Sade, D. S. 1972a. A longitudinal study of social behavior of rhesus monkeys. In: The Functional and Evolutionary Biology of Primates (Ed. by $\mathrm{R}$. Tuttle), pp. 378-398. Chicago: Aldine-Atherton.

Sade, D. S. $1972 \mathrm{~b}$. Sociometrics of Macaca mulatta: I. linkages and cliques in grooming matrices. Folia Primatol., 18, 196-223.

Van Lawick-Goodall, J. 1968. The behaviour of freeliving chimpanzees in the Gombe Stream Reserve. Anim. Behav. Monographs, 1, 165-311.

Walters, J. 1980. Interventions and the development of dominance relationships in female baboons. Folia Primatol, 34, 61-89

Yamada, M. 1963. A study of blood-relationships in the natural society of the Japanese macaque. Primates, 4, 43-65.

(Received 26 November 1979; revised 31 March 1980; MS. number: A2409)

Appendix: Social Behaviours Used as Variables

Groomed: pushed back recipient's fur with one hand while picking parasites, etc., from recipient's coat and skin with the other hand.

Presented For Grooming: stood quadrupedally with one side very close to recipient, sat tilting head away from recipient, or placed hindquarters near recipient's face while looking away from recipient.

Embraced: put one or both arms around recipient.

Touched: placed one hand briefly on some part of recipient (mutually exclusive of other behaviours).

Affiliative-Sexual Behaviour: includes four behaviours associated with sex that occur in non-sexual contexts as well, namely, mounted, stood behind (an incomplete mount), grasped (placed one hand on each of recipient's thighs), and presented (placed hindquarters near recipient's face, looking back repeatedly).

Intervened: directed agonistic behaviours at third individual during an agonistic interaction between recipient and a third individual.

Mild Aggression: includes non-contact forms of aggression, which are chased, counterchased (chased while screaming), lunged, counterlunged (lunged while screaming), and threatened, and mild forms of contact aggression, which are hit and shoved. 
ANIMAL BEHAVIOUR, 29, 1

Severe Aggression: includes more severe forms of contact aggression, which are bit, chewed (mouthed), grabbed, grappled, and held down. Displaced: moved toward recipient, who glanced at approaching individual and then quickly moved away.

Muzzle-Sniffed: put closed muzzle close to recipient's closed muzzle. 